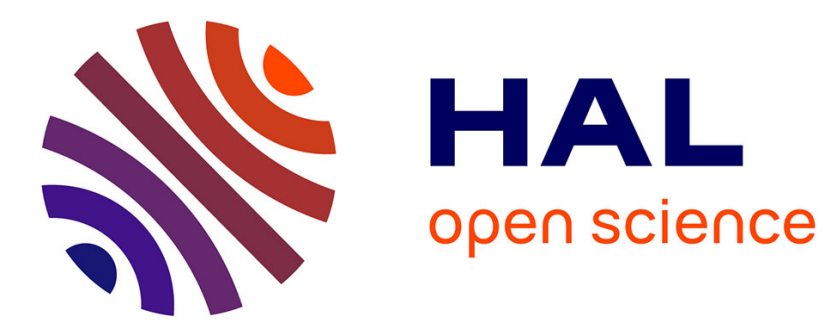

\title{
The influence of light on small hive beetle (Aethina tumida) behavior and trap capture
}

\author{
Adrian Duehl, Richard Arbogast, Audrey Sheridan, Peter Teal
}

\section{To cite this version:}

Adrian Duehl, Richard Arbogast, Audrey Sheridan, Peter Teal. The influence of light on small hive beetle (Aethina tumida) behavior and trap capture. Apidologie, 2012, 43 (4), pp.417-424. 10.1007/s13592-011-0106-9 . hal-01003529

\section{HAL Id: hal-01003529 \\ https://hal.science/hal-01003529}

Submitted on 1 Jan 2012

HAL is a multi-disciplinary open access archive for the deposit and dissemination of scientific research documents, whether they are published or not. The documents may come from teaching and research institutions in France or abroad, or from public or private research centers.
L'archive ouverte pluridisciplinaire HAL, est destinée au dépôt et à la diffusion de documents scientifiques de niveau recherche, publiés ou non, émanant des établissements d'enseignement et de recherche français ou étrangers, des laboratoires publics ou privés. 


\title{
The influence of light on small hive beetle (Aethina tumida) behavior and trap capture
}

\author{
Adrian J. Duehl ${ }^{1}$, Richard T. Arbogast ${ }^{1}$, Audrey B. Sheridan ${ }^{2}$, Peter E. Teal ${ }^{1}$ \\ ${ }^{1}$ USDA-ARS-CMAVE, 1600 SW 23rd Drive, Gainesville, FL 32609, USA \\ ${ }^{2}$ Mississippi State University, Starkville, MS 39762, USA
}

Received 2 May 2011 - Revised 16 September 2011 - Accepted 17 October 2011

\begin{abstract}
The small hive beetle (Aethina tumida, Murray) is a major pest of honeybee (Apis mellifera) colonies, particularly in the Southeastern USA. We evaluated the small hive beetle's (SHB) response to different wavelengths of the light spectrum and found that SHB larvae and adults were most attracted to the $390 \mathrm{~nm}$ wavelength. Early instar larvae were not significantly attracted to light, while wandering larvae and adults exhibited strong positive phototaxis. The light response of the nonfeeding larval stage indicates readiness to leave a hive and search for pupation locations. Laboratory competitive trapping trials showed that light increased trap catches more than ten-fold for adults and twenty-fold for larvae compared to traps without light. Field trials demonstrated different features of photo attraction; at field sites, hanging traps with light-emitting diodes incorporated into the capture area did not capture more adults than control traps. Light traps in enclosed spaces effectively trapped both adults and larvae. Light shows promise for beetle control in locations where comb is stored or honey extracted.
\end{abstract}

Aethina tumida / small hive beetle / LED / phototaxis

\section{INTRODUCTION}

Small hive beetles (SHB, Aethina tumida Murray; Coleoptera: Nitidulidae) orient towards natural light (Lundie, 1940; Schmolke, 1974), and their response to light changes both within and between developmental stages. Adults are positively phototactic when they emerge from the soil but then become negatively phototactic as they grow older (Lundie, 1940; Schmolke, 1974). Larvae show a reverse pattern; younger larvae are negatively phototactic, while wandering larvae move towards light (Schmolke, 1974). This behavior has been exploited by some beekeepers, who use broad spectrum light for larval population control in honey process-

Corresponding author: A.J. Duehl, adrian.duehl@ars.usda.gov Manuscript editor: Peter Rosenkranz ing houses. Problems associated with using such broad spectrum light sources include the expense of quartz halogen lights and attracting larvae only after they have ceased feeding (Somerville, 2003). Adult SHB have not been sampled by light trapping, despite the importance of maintaining even lighting conditions for unbiased bioassays, as reported by several authors (Suazo et al., 2003; Spiewok and Neumann, 2006). Additionally, the importance of ambient light conditions to dispersing adults and trapping locations have been considered (Arbogast et al., 2009b; Spiewok et al., 2008) but the efficacy of adding lights to traps has not.

New technology in the form of light-emitting diodes (LEDs) capable of emitting specific wavelengths attractive to insects allows for the effects of different wavelengths of light to be studied, as well as incorporated into field traps easily and inexpensively. Many insects perceive 
and are attracted to light wavelengths in the near ultraviolet (UV) and UV portions of the electromagnetic spectrum (Briscoe and Chittka, 2001). These elements of visual perception and attraction can be useful in increasing trap efficiency. Current lure-based traps use the chemical cues that lead SHB to hives, capitalizing on the attraction to weak or already infested hives that produce higher levels of alarm pheromone (Nolan and Hood, 2008; Torto et al., 2007b). Beetles show strong attraction to a mixture of pollen dough and the yeast Kodamaea omeri (Torto et al., 2007b). The fermentation of the pollen dough by the yeast produces a suite of attractive volatile chemicals that includes the honeybee alarm pheromone chemical, isopentyl acetate, and approximates the attractiveness of a hive infested with beetles (Torto et al., 2007a). Traps using this chemical lure effectively sample beetles in the field, but are not effective enough to out-compete beehives when traps are placed in an apiary (Arbogast et al., 2007). The addition of light to conventional traps may make them competitive with beehives in attracting beetles. The objectives of this study were to determine the most attractive wavelengths for different SHB life stages and to evaluate using LEDs emitting these wavelengths in traps designed for larvae and for adults.

\section{MATERIAL AND METHODS}

\subsection{Arena assay}

All beetles used in the bioassays described below were obtained from a laboratory colony here at the United States Department of Agriculture (USDA) Agricultural Research Service (ARS) Center for Medical Agricultural and Veterinary Entomology. The colony is augmented with field-caught beetles every summer. Laboratory bioassays were conducted using a cloverleaf arena made from cast $15.2 \mathrm{~cm}$ diameter, $6 \mathrm{~mm}$ thick plexiglass tubing. The tubing was cut into $2.5 \mathrm{~cm}$ slices; then each slice was cut in half, and the four resulting pieces were glued together at their ends to form a clover-leaf arena (Figure 1). LEDs were attached to the arena at

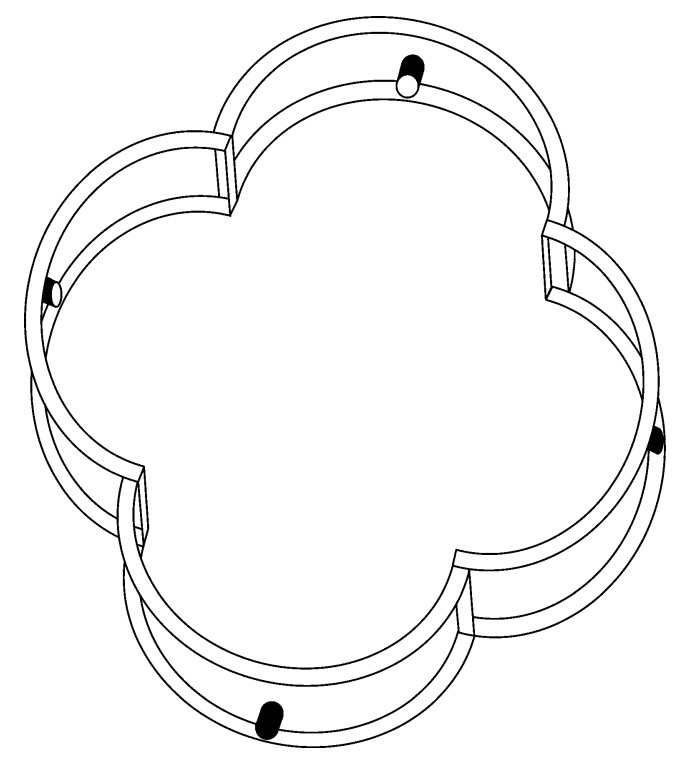

Figure 1. The cloverleaf arena used for the laboratory light preference trials. At the apex of each half circle, there is an LED positioned close to the ground. The arena is $2.5 \mathrm{~cm}$ deep and the half circles have a diameter of $15.2 \mathrm{~cm}$. The arena is constructed of plexiglass and the LEDs are $5 \mathrm{~mm}$ in diameter.

the apex of each half circle with LED holders (Radio Shack, Fort Worth, TX, USA; model 276080). For bioassays, LEDs were adjusted to emit $10 \mathrm{~mW} / \mathrm{cm}^{2}$, except for the $410 \mathrm{~nm}$ that emitted $34 \mathrm{~mW} / \mathrm{cm}^{2}$ at maximum potentiometer resistance $(5 \mathrm{k} \Omega)$. All laboratory light bioassays lasted $5 \mathrm{~min}$ and were conducted with replicates of five individuals each. Individual beetles were scored by recording the total number of straight paths to each LED during a 5-min trial. Individuals could be counted more than once, but only if they moved away from the LED and then returned. The LEDs emitted either near UV or visible light; specific wavelengths were $410 \mathrm{~nm}$ (blue), near UV (390 and $380 \mathrm{~nm}$ ) or UV $(360 \mathrm{~nm})$. LEDs were randomly repositioned between trials. A second set of bioassays compared the best of the UV group (390 nm) to visible $460 \mathrm{~nm}$ (white), $569 \mathrm{~nm}$ (green), and $587 \mathrm{~nm}$ (yellow) wavelengths. Statistical differences in attraction were analyzed with one-way analysis of variance, Proc GLM, using Tukey's comparison of the least squares means (SAS 2004). 
The groups of individuals tested in the cloverleaf arena were adults freshly emerged from soil (10 replicates), larvae 3-7 days old (10 replicates), and wandering larvae $7-15$ days old (20 replicates). Preliminary assays were also conducted on colony beetles with ages between 2 weeks and 2 months old, and similar patterns of light attraction were observed for the individuals within this age bracket.

\subsection{Shed assays}

Both older adults and wandering larvae from the laboratory colony were assayed in a shed, $9 \mathrm{~m}$ long by $3.2 \mathrm{~m}$ wide, that averaged $25^{\circ} \mathrm{C}$ and $69 \% \mathrm{RH}$ for the adult bioassays and $29^{\circ} \mathrm{C}$ and $27 \% \mathrm{RH}$ for the larval bioassays. The differences in humidity were due to seasonal changes in nonhumidified sheds. For assays, the windowless shed was completely darkened with no other light source other than that from the LED's. Four replicates, each consisting of the release of 100 individuals in the center of the shed on the floor at the beginning of the trial, were conducted for both adults and larvae. Adult bioassays lasted $24 \mathrm{~h}$ and larval bioassays lasted $48 \mathrm{~h}$; in the latter, larvae were removed at 24 and $48 \mathrm{~h}$. For trapping adults, two pipe traps (Arbogast et al. 2007) baited with pollen dough that had been inoculated with $K$. omeri and containing a kill strip (Vaportape II, Hercon, Emigsville, PA, USa) were hung from the ceiling along the long axis of the shed $1.5 \mathrm{~m}$ above the floor and $3 \mathrm{~m}$ apart. One trap contained a radial light array emitting a dominant wavelength of 390 nm (Bioquip, Rancho Dominguez, CA, USA; 2790v390); the other did not. The light array was attached to a $6 \mathrm{~V}, 10 \mathrm{Ah}$ rechargeable battery. Beetles were collected from the bottom of each trap after $24 \mathrm{~h}$. The larval traps were pitfall traps constructed from square plastic containers, $11 \mathrm{~cm}$ long by $7.5 \mathrm{~cm}$ wide and $2.5 \mathrm{~cm}$ deep with $8.5 \mathrm{~cm}$ long white plastic ramps (Figure 2) and for the light trap, a $4 \mathrm{~cm}$ piece of 6-mm hard plastic tubing was affixed to the center to hold a radial light array (Bioquip, 2790v390). The traps were located at the same relative places as the hanging traps but on the floor. The center of each trap was filled with soapy water (Alconox, White Plains, NY, USA). The light arrays were comprised of LEDs emitting light at $390 \mathrm{~nm}$, the most attractive wavelength in the laboratory trials.
Trials for adults and larvae were each replicated four times in the same shed. Differences in the relative attractiveness of traps were determined using $t$ tests and the Cochran method as samples had unequal variances (SAS 2004).

\subsection{Field testing}

\subsubsection{Woodland trapping of adults}

To test UV light and control traps in a field setting, hanging adult beetle traps, as described above, were placed in three field locations. The only difference in trap setup between this and the previously described shed trial was that the lighted traps were powered by $20 \mathrm{Ah}$ batteries so that they could be left unattended for longer periods of time. Traps were placed in wooded sites near La Crosse, FL, USA; site 1 was well shaded and adjacent to a tree-lined stream; sites 2 and 3 were partially shaded dry wooded locations $200 \mathrm{~m}$ apart and $2 \mathrm{~km}$ from site 1 . No honeybees were attracted to a yellow sugar feeder placed at the trapping sites for 2 weeks before the study started and the nearest managed hives were $8 \mathrm{~km}$ away. There were four traps at each site, two with pollen dough and UV LED arrays and two with pollen dough alone. Traps were checked every week for 8 weeks between May 7th and July 10th 2010. At each assessment, the number of small hive beetles in each trap was counted.

\subsubsection{Honey house trapping}

A honey house in Columbia County, FL, USA was used to test the effectiveness of the larval UV trap in capturing wandering-stage larvae in a commercial setting. The honey house was approximately $11 \times 6 \mathrm{~m}$, the main spring season was over so it was only used occasionally. Tests were run from July through December 2010. Initially, a prototype trap with a UV array was placed on the floor under a honey tank located near a wall, where it was out of the way of workers and easily accessible to larvae. This trap was replaced 1 week later by a more durable acrylic trap. Honeybees within the honey house were strongly attracted to the $390 \mathrm{~nm}$ light emitted by the array, and large numbers became trapped in the pitfall. To overcome this problem, the trap was placed on a 
Figure 2. The larval pitfall trap used for the shed light trial with wandering larvae. The lighted trap had an LED array (Bioquip) raised 2 in. above the center of the pitfall box in the arena. The trap was constructed from white plastic sheets attached to a pipette tip box lid in the center.

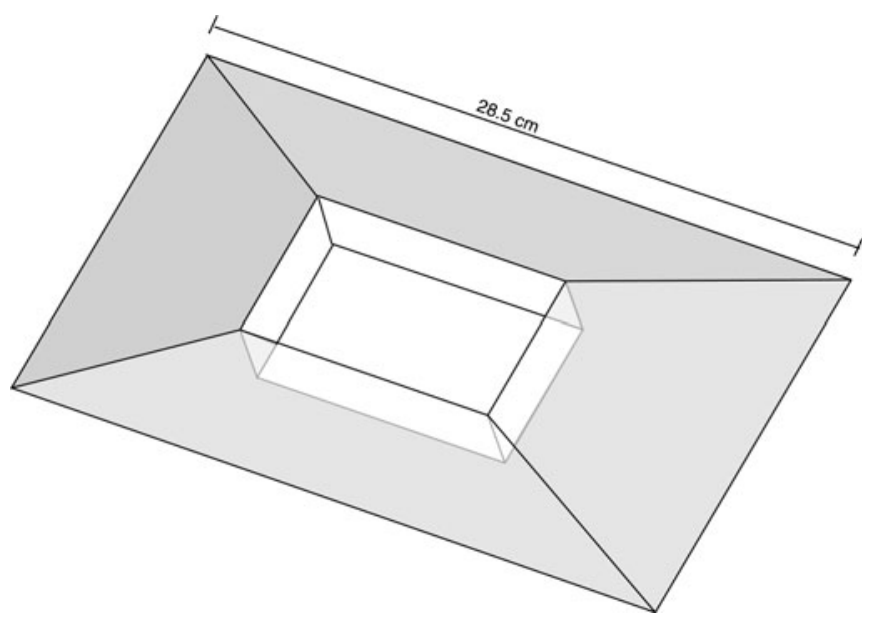

plywood base and covered by a screen box (eight mesh stainless steel, MSC Industrial Supply Co., Melville, NY, USA) to exclude bees. The bottom edge of the excluder fitted into grooves cut in the base, which held it in place and prevented bees from crawling under it. The edges of the base were angled to allow the beetle larvae easy access.

The honey house was also used to compare the effectiveness of fermenting pollen dough with that of UV light in luring adult beetles into flight traps. Two traps with pollen dough and one with a UV array were hung $3.4 \mathrm{~m}$ above the floor and a second trap with UV light was hung under the honey tank $0.5 \mathrm{~m}$ above the floor. The first three traps were located $1.5 \mathrm{~m}$ from the side walls and $3 \mathrm{~m}$ from the end walls, the fourth was in a similar location but under the honey tank due to space restrictions.

All traps were checked at intervals of 1-2 week and the numbers of larvae or adults captured were recorded. The number of larvae trapped over time was related to changes in warehouse content and activities. The total number of adults captured by the pollen dough and UV traps were compared using a $\chi^{2}$ one-sample test.

Statistical comparisons were made for all field trials, except the honey house larvae-trapping trials. Chi-square values were calculated for field adult trapping trials because of unequal variances between treatment groups and many replicates with zerotrapped beetles (Siegel, 1956). For screen house adult trapping and larval trap shed efficacy testing, $t$ tests were used to determine statistical differences. Pooled $t$ tests were used because variances were equal between treatments.

\section{RESULTS}

\subsection{Arena assays}

The cloverleaf arena was an effective assay tool as it enabled the successful identification of significantly attractive wavelengths. The adults showed a significant light response $\left(F_{3,36}=9.98\right.$, $P<0.0001)$ and most often moved towards $390 \mathrm{~nm}$ wavelengths $(\alpha<0.05)$ over others in the near UV (Figure 3). When the $390 \mathrm{~nm}$ wavelength of light was compared to others in the visible spectrum, the former was most preferred by adult beetles $(\alpha<0.05)$, and again adults were significantly attracted to light $\left(F_{3,36}=\right.$ 27.07, $P<0.0001$; Figure 3).

Wandering larvae showed patterns of light attraction similar to those of adults in the assay arena. They were significantly attracted to LEDs emitting in both the visible and near UV spectra $\left(F_{3,76}=10.50\right.$ and 15.50 respectively and $P<$ $0.0001)$. Among the near UV and UV wavelengths, they significantly preferred the 380 and $390 \mathrm{~nm}(\alpha<0.05$; Figure 4). The $390 \mathrm{~nm}$ wavelength was preferred over the visible wavelengths $(\alpha<0.05$; Figure 4$)$. We found that feeding larvae, 3-7 days old, had undirected movement with no indication of a phototactic response. Their responses to light did not differ 

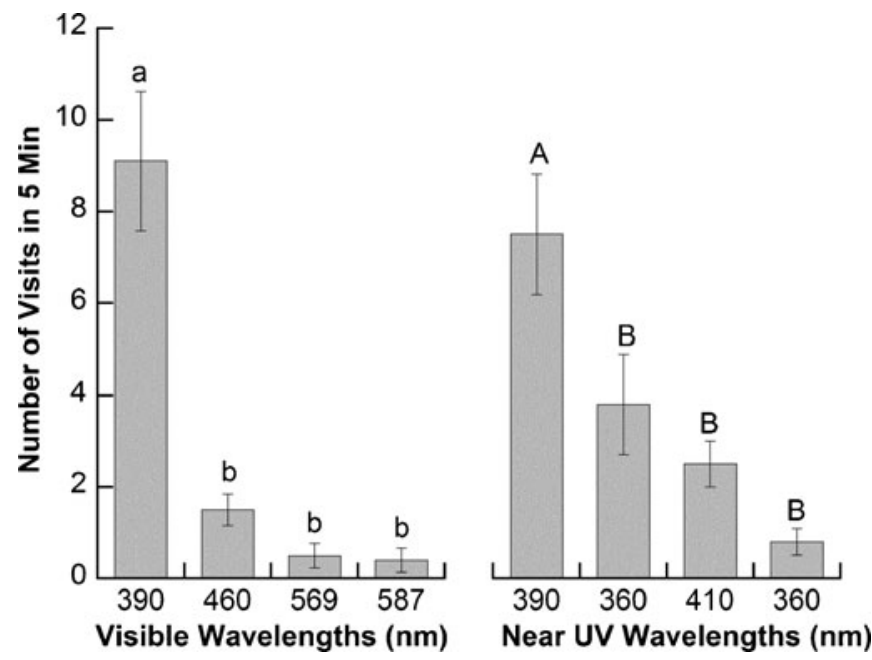

Figure 3. Small hive beetle adults show significant attraction to LEDs emitting light in the near UV and visible spectra $\left(F_{3,36}=27.07\right.$ and $\left.9.98, P<0.0001\right)$. These data represent the number of visits by beetles per trial to LEDs in a cloverleaf arena. Ten trials were run to each set of LEDs and five beetles were involved in each trial. The near UV, $390 \mathrm{~nm}$ LED, was the most attractive of both sets of LEDs (data with the same letter are not different at $\alpha<0.05$ ).

significantly from zero $\left(F_{3,36}=0.80\right.$ and 1.32 for visible wavelengths and near UV, respectively, and $P=0.4994$ and 0.2829 , respectively). These results indicate that adult $\mathrm{SHB}$ and wandering
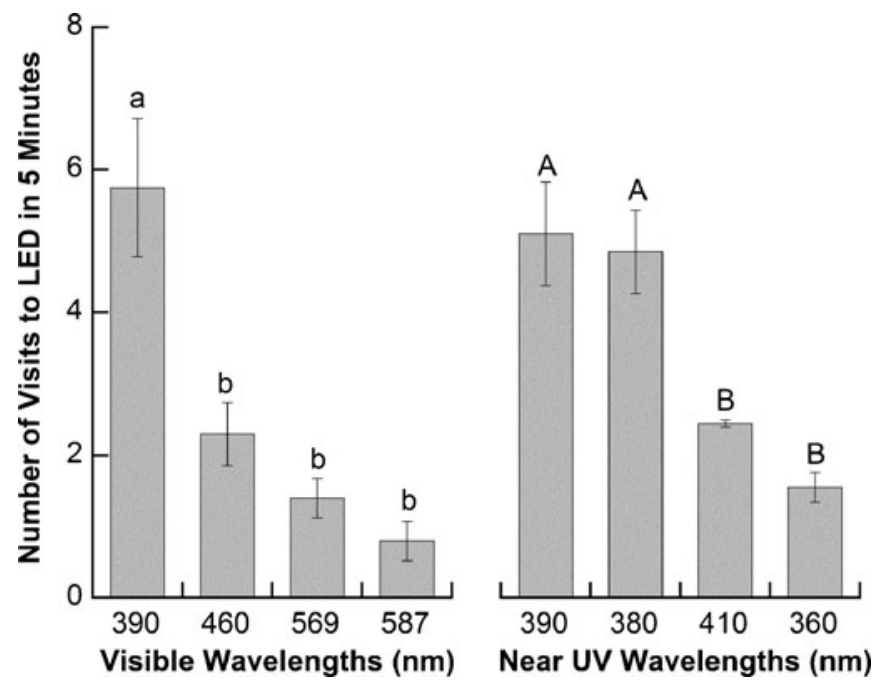

Figure 4. The attraction of wandering SHB larvae to LEDs emitting light in the near UV and visible spectra. These data represent the number of visits by larvae per trial to each LED in a cloverleaf arena. Twenty trials were run to each set of LEDs and five larvae were involved in each trial. Wandering larvae showed significant light response in both trials $\left(F_{3,76}=10.50 \mathrm{UV}\right.$ and 15.50 visible, $\left.P<0.0001\right)$. The near UV, $390 \mathrm{~nm} \mathrm{LED}$, was the most attractive of both sets of LEDs but not significantly different from the $380 \mathrm{~nm}$ (data with the same letter are not different at $\alpha<$ 0.05 ), and is likely the wavelength used by beetles as they look for pupation locations. 
larvae move towards specific wavelengths, but the results did not address the willingness of adult beetles to fly to a preferred light source, nor the ability of larvae to disperse over greater distances.

\subsection{Shed bioassays}

To evaluate flying behavior - the principal form of locomotion for long-distance dispersal in adult beetles-we suspended light-emitting traps in darkened sheds. This required beetles to fly rather than walk into traps, a situation more closely approximating field trapping conditions. These trials demonstrated that adding light to a pipe trap significantly increased trapping efficiency $\left(t_{1}=11.80, P=0.0013\right)$; the lighted trap outperformed the control trap, capturing more than tenfold the number of beetles (Figure 5). Larval shed trials examined longer distance attraction and the effectiveness of a light baited pitfall trap. Larval shed trapping was even more
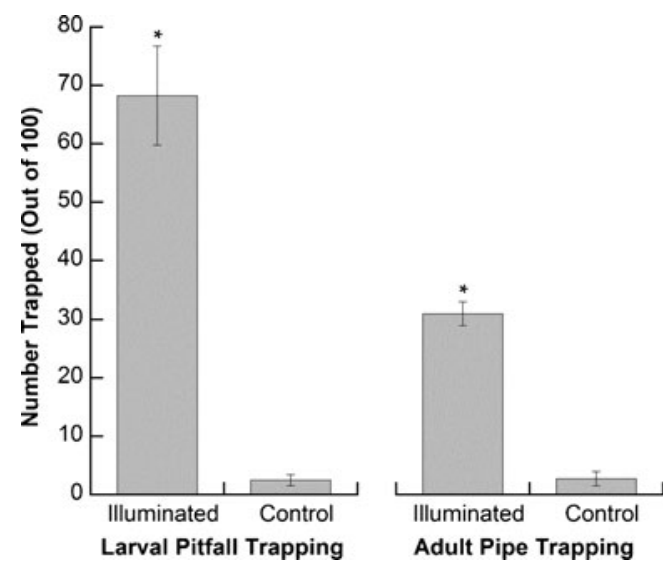

Figure 5. Shed trials evaluating pitfall traps for larvae and pipe traps for adults. To trap adults, a pipe trap baited either with inoculated pollen dough alone, or inoculated pollen dough with an LED array emitting light at a dominant wavelength of $390 \mathrm{~nm}$, was used. For larvae a pitfall trap with the same LED array and a pitfall trap without the LED array were used. One hundred beetles were released in each of four trials. The light traps in each set trials caught significantly more beetles $\left(T_{3}=11.80, P=0.0013\right.$ pipe trap; $T_{3}=7.70, P=0.0046$ pitfall trap, significant differences indicated by asterisks). effective than adult trapping when lights were added. Significantly more larvae were captured in the light trap $\left(t_{1}=7.70, P=0.0046\right)$, and about two thirds of the total number released were recaptured (Figure 5).

\subsection{Field trials}

\subsubsection{Woodland trapping of adults}

The field trapping experiment was conducted in woodlands to sample low density beetles in locations $8 \mathrm{~km}$ from beehives. The UV efficacy comparison was a secondary goal of this trapping experiment, but we were able to show that, in paired trapping trials, the control trap was the more attractive one (UV+ pollen dough, 12 beetles, pollen dough alone, 27 beetles, $\chi_{{ }_{1}}^{2}=$ 5.77, $P=0.016$ ), although again neither caught many beetles.

\subsubsection{Honey house trapping}

The UV trap captured significantly more beetles (UV, 124 beetles, pollen dough, 49 beetles, $\chi_{1}^{2}=32.51, P=<0.001$ ), although there was no basis to estimate trap efficiency (numbers present unknown) in the honey house or the likelihood that trap deployment decreased comb infestation levels. The larval trap captured 7,451 larvae over the 13 observation periods but the capture per period was highly variable. This variability stemmed from the activities in the honey house: moving comb in from the field before honey extraction, disturbance during extraction, storage after extraction.

\section{DISCUSSION/CONCLUSION}

The general phototactic responses of both larval and adult SHB have previously been reported by Lundie (1940) and Schmolke (1974). Results from our studies extend our understanding of this strong light response in both adults and larvae by identifying the wavelengths to which they are most attracted and evaluating their responses in new population management strategies. The difference in light 
response between feeding larvae and wandering larvae demonstrates the role of phototaxis in their life cycle. The absence of phototactic behavior characterizes feeding larvae, but this changes when larvae prepare for pupation. The positive phototaxis that draws mature larvae out of the hive is short-lived, lasting only until the larvae reach suitable pupation sites. At that point, larvae move away from light and into the soil. However, the presence of large wandering larvae in a hive that still contains food suggests that the timing of phototaxis reversal is more complicated than it appears, or that larvae exit the hive due to specific additional stimuli. The larval light response should be studied further to determine why at least some larvae do not leave the hive as soon as they are mature, especially because the results of our shed trials indicated that most larvae responded to the light cue within $48 \mathrm{~h}$. The lack of any light response by feeding larvae shows that light will not enhance any control method, either within hives or in storage situations. In the cloverleaf arena, the light intensity from the LEDs was low, seemingly below the negatively phototactic behavior previously described (Schmolke, 1974). However, the strong response of wandering larvae could be used to control their movement as they disperse from hives or combs in honey houses. Trapping wandering larvae in honey houses could decrease the SHB pressure on hives located near the honey houses, or provide a sink by which beetles are permanently removed from the operation.

Light attraction in adults indicates visual cues are important to dispersal. The crepuscular and nocturnal habit of SHB (Suazo et al., 2003) and these light attraction results suggest that light trapping would be effective. The results from both bioassay and shed trapping support implementing light traps to disrupt hive invasion by adults. However, our field experiments did not support this hypothesis, showing that control traps with pollen dough perform as well if not better than illuminated traps in open settings. However, for adult population control in enclosed spaces, traps with light as a visual cue will capture more beetles than traps with olfactory cues alone.
Insects can perceive and are attracted to light of various wavelengths and in most insects this includes near UV (Briscoe and Chittka, 2001). Flour beetle (Tribolium castaneum) attraction to near-UV wavelengths is related to a spectral reflectance peak of flour at the same point (Duehl et al., 2011). The negative phototaxis of older small hive beetle adults (Lundie, 1940; Schmolke, 1974) was not observed in our assays with specific wavelengths. Visual cues are likely important if beetles move between nest sites and alternate hosts following the seasonality of their native habitat (Buchholz et al. 2008; Arbogast et al., 2009a). This research clearly indicates that using the attractive, dispersal-related, near-UV wavelengths will not increase trap capture under field conditions. More research on visual responses throughout the SHB lifecycle will increase our understanding of its behavior, particularly if light response varies with catastrophic events such as hive collapse that cause the beetles to disperse.

Light attraction requires a combination of insect perception of emitted light spectra and sufficient contrast for the insect to notice the light source in relation to its surroundings. These wavelengths likely serve as cues indicating escape from enclosed spaces, hence their effectiveness in sheds and honey houses, but no increase and a possible decrease in field trap capture. This relationship between light attraction and insect perception of an enclosed space is an interesting avenue for further research.

Use of trade, firm, or corporation names in this publication is for the information and convenience of the reader. Such use does not constitute an official endorsement or approval by the USDA or ARS of any product or service to the exclusion of others that may be suitable.

\section{ACKNOWLEDGEMENTS}

The authors would like to thank Tredina Davis and Curtis Murphy for their assistance with bioassays. 
Influence de la lumière sur le comportement et le piégeage du petit coléoptère des ruches (Aethina tumida)

\section{Aethina tumida / LED / phototaxie / piège / ennemi de la ruche}

Der Einfluss von Licht auf das Verhalten des Kleinen Beutenkäfers (Aethina tumida) und auf Fallenfänge.

\section{Aethina tumida / Kleiner Beutenkäfer / LED / Phototaxis}

\section{REFERENCES}

Arbogast, R.T., Torto, B., Willms, S., Teal, P.E.A. (2009a) Trophic habits of Aethina tumida (Coleoptera: Nitidulidae): their adaptive significance and relevance to dispersal. Environ Entomol 38, 561-568

Arbogast, R.T., Torto, B., Teal, P.E.A. (2009b) Monitoring the small hive beetle, Aethina tumida (Coleoptera: Nitidulidae) with baited flight traps: effect of distance from bee hives and shade on the numbers of beetles captured. Fla Entomol 92, 165-166

Arbogast, R.T., Torto, B., van Englesdorp, D., Teal, P.E. A. (2007) An effective trap and bait combination for monitoring the small hive beetle, Aethina tumida (Coleoptera: Nitidulidae). Fla Entomol 90, 404-406

Briscoe, A.D., Chittka, L. (2001) The evolution of color vision in insects. Annu Rev Entomol 46, 471-510

Buchholz, S., Schäfer, M.O., Spiewok, S., Pettis, J.S., Duncan, M., Ritter, W., Spooner-Hart, R., Neumann, P. (2008) Alternative food sources of Aethina tumida (Coleoptera: Nitidulidae). J Apic Res 47, 202-209

Duehl, A. J., Cohnstaedt, L. W., Arbogast, R. T., Teal, P. E. A. (2011) Evaluating light attraction to increase trap efficiency for Tribolium castaneum (Coleoptera: Tenebrionidae). J Econ Entomol (in press).

Lundie, A. E. (1940) The small hive beetle, Aethina tumida. Sci. Bull. 220, Union of South Africa, Department of Agriculture and Forestry, Rodesia.

Nolan, M.P., Hood, W.M. (2008) Comparison of two attractants to small hive beetles, Aethina tumida, in honey bee colonies. J Apic Res 47, 229-233

SAS (2004) SAS 9.1.3 help and documentation. SAS Institute Inc, Cary, NC

Schmolke, M. D. (1974) A study of Aethina tumida: the small hive beetle, University of Rodesia.

Siegel, S. (1956) Nonparameteric statistics for the behavioral sciences. McGraw-Hill, NY

Somerville, D. (2003) Study of the small hive beetle in the USA, a report for the rural industries research and development corporation. Report number 03/ 050. NSW Agriculture, Goulburn, Australia.

Spiewok, S., Duncan, M., Spooner-Hart, R., Pettis, J., Neumann, P. (2008) Small hive beetle, Aethina tumida, populations II: dispersal of small hive beetles. Apidologie 39, 683-693

Spiewok, S., Neumann, P. (2006) Infestation of commercial bumblebee (Bombus impatiens) field colonies by small hive beetles (Aethina tumida). Ecol Entomol 31, 623-628

Suazo, A., Torto, B., Teal, P.E.A., Tumlinson, J.H. (2003) Response of the small hive beetle (Aethina tumida) to honey bee (Apis mellifera) and beehiveproduced volatiles. Apidologie 34, 525-533

Torto, B., Arbogast, R.T., Alborn, H., Suazo, A., van Engelsdorp, D., Boucias, D., Tumlinson, J.H., Teal, P.E.A. (2007a) Composition of volatiles from fermenting pollen dough and attractiveness to the small hive beetle Aethina tumida, a parasite of the honeybee Apis mellifera. Apidologie 38, 380-389

Torto, B., Boucias, D., Arbogast, R.T., Tumlinson, J.H., Teal, P.E.A. (2007b) Multitrophic interaction facilitates parasite-host relationship between an invasive beetle and the honey bee. Proc Natl Acad Sci 104, 8374-8378 